\title{
Patient satisfaction with anesthesia services
}

$M$ arie-Christine Taillefer $B S c, \ddagger$ Gilles D upuis PhD $\ddagger$

Purpose: The evaluation of services by patients is an essential component of continuous quality improvement in anesthesiology. Little is known, however, about how to achieve this objective. 0 ur goal was to conduct a systematic review of all available studies on patient satisfaction with anesthesia services, thereby ascertaining the present level of knowledge in this field and suggesting ways of improving current measurement methodologies.

Source: We reviewed relevant major data banks - Medline, Dissertation Abstract, Psyclit and Cochrane between 1980 and 2000 and bibliographies from primary sources. We used the following keywords for our search: quality improvement, anesthesia, quality, patient perceptions, consumer satisfaction, continuous quality improvement, outcome measures.

Principal findings: The review yielded 14 pertinent studies. Studies were divided into two groups $(A \& B)$, according to the quality of the psychometric evaluation (tests performed to verify the reliability and validity of an instrument). W hile all studies reported high levels of patient satisfaction with anesthesia services, many used methods of questionable value. N one of the 14 studies controlled for any confounding variables, such as social desirability. Four studies had seriously biased their data collection and the majority of the studies lacked rigour in the development of the instrument used to measure patient satisfaction. 0 nly one study presented a definition of the concept measured, and none provided a conceptual model of patients' satisfaction with anesthesia services.

Conclusion: The currently available studies of patient satisfaction are of questionable value. 0 nly rigo rous methods and reliable instruments will yield valid and clinically relevant findings of this important issue in anesthesiology.

O bjectif : L'évaluation de la qualité des services, par les patients, est une composante essentielle de l'amélioration de la qualité des services en anesthésiologie. Cependant, nos connaissances dans ce domaine sont limitées. N ous proposons une évaluation systématique de la littérature sur ce sujet dans le but d'amélio rer la méthodolo gie reliée à la mesure de ce concept.

Source des références: N ous avons procédé à une revue systématique de plusieurs banques de données Medline, Dissertation Abstract, Psyclit, et Cochrane - pour la période de 1980 à 2000 ainsi que les bibliographies des références primaires. Les mots-clés suivants ont été utilisés : amélioration de la qualité, anesthésie, qualité, perceptions des patients, satisfaction de la clientèle, amélioration continue de la qualité, mesure des résultats.

Principaux résultats : La revue systématique de la littérature a permis de recenser 14 études pertinentes. Elles ont été divisées en deux groupes $(A \& B)$ selon la qualité de l'évaluation psychométrique (vérification de la fidélité et de la validité des instruments). Toutes ces études présentent des taux élevés de satisfaction des patients à l'égard des services anesthésiques. Cependant, les méthodes choisies pour l'évaluation de la satisfaction des patients présentent des biais importants. Aucune de ces études n'a présenté de moyens de contrôle des variables confondantes telles que la désirabilité sociale. Il y a présence de biais dans la collecte de données de quatre études et la majorité démontre peu de rigueur dans le développement de l'instrument utilisé. Une seule étude a fourni une définition du concept mesuré et aucune n'a proposé de cadre conceptuel.

Conclusion : Les études publiées à ce jour sur la satisfaction des patients sont d'une valeur do uteuse. Il est essentiel d'employer des méthodes rigoureuses ainsi que des instruments fiables, afin de générer des résultats valides et cliniquement pertinents sur ce domaine important en anesthésiologie.

From the D epartment of Anesthesiology, $\dagger$ Faculty of M edicine and the Faculty of $N$ ursing, ${ }^{*} U$ niversity of $M$ ontreal, and the D epartment of Psychology, $¥$ U niversité du Q uébec à M ontréal, M ontreal, C anada.

A ddress cor respondence to: $\mathrm{Dr}$ J ean-F rançois $\mathrm{H}$ ardy, D epartment of Anesthesiology, Faculty of M edicine, U niversity of M ontreal, C.P. 6128, succursale Centre-Ville, M ontreal, Q uebec, H 3C 3J 7, Canada. E-mail: jean-francois.hardy@umontreal.ca

This review was supported in part by the D epartment of Anesthesiology, M ontreal $\mathrm{H}$ eart Institute, M ontreal, Canada and by the Alma

$M$ ater Fund of the Faculty of N ursing of the $U$ niversity of $M$ ontreal, $M$ ontreal, Canada.

A ccepted for publication October 22, 2000. 
$\mathrm{T}$

H E major data banks contain a vast array of articles, published between 1980 and 2000 , that examined patient satisfaction with medical care. Few of these publications, however, cover patient satisfaction with services provided by anesthesiologists. D espite the paucity of publications in the field, several authors believe that patient satisfaction is an attribute of the quality of care in anesthesia. ${ }^{1-3}$

Recently, a review on patient satisfaction and anes thesia care was published, ${ }^{4}$ focusing on the appropriateness of different methodologies used to measure patient satisfaction. In contrast, this present article seeks to provide a more critical review of the methodology, the development of the instrument used by the authors and psychometrics (when available) and the results obtained by selective studies treating this concept.

\section{Sources}

O ur methods were inspired by Cook. ${ }^{5} \mathrm{H}$ er suggested format for a systematic review of the literature includes: a description of the data sources, study selection, data extraction-synthesis and a presentation of the results.

\section{D ata sources}

We searched Medline, Current Contents, the Cochrane Data Base, and Dissertation Abstract for studies published between 1980 and $M$ arch 2000. We searched the bibliographies of primary and review articles for other relevant studies. O ur search was restricted to French and English publications.

We used the following key words to retrieve articles: quality improvement, anesthesia (including anaesthesia), quality, patient satisfaction, patient perceptions, consumer satisfaction, continuous quality improvement, outcome measures. We also combined some of the main keywords: quality and anesthesia, quality improvement and anesthesia, patient (and consumer) satisfaction and anesthesia, quality and patient satisfaction and anesthesia (including anaesthesia).

\section{Study sel ection}

We selected studies that emphasized patients' satisfaction with anesthesia services. Included were studies covering both ambulatory and hospitalized patients. Since relatively few studies focused mainly on patient satisfaction with anesthesia services, we did not use any selection criteria and included all publications in the present review. We excluded drug trials regarding patient satisfaction over pain management. These studies used relief of pain as the sole indicator of patient satisfaction.
Data extraction and synthesis

Data were extracted following three specific categories: source, population (characteristics of the sample), a summary of the main results vis-a-vis patient satisfaction and the instrument used. Studies were divided in two groups (A and B). Group A includes those studies in which no psychometric testing (tests performed to evaluate the reliability and validity of instruments) was done on the scales employed to measure patient satisfaction. G roup B includes the studies that performed certain psychometric tests on the scale employed to measure patient satisfaction.

\section{Principal findings}

We found 14 studies that focused on patient satisfaction with anesthesia services. A synthesis of the data extracted from these studies is presented in the Table. Studies were divided in two groups (A \& B) according to the quality of the psychometric evaluation (tests performed to verify the reliability and validity of an instrument) of the instrument used to collect data. Group A includes studies where the authors did not perform any psychometric tests on the instrument they used. Group B includes the studies where the authors performed some psychometric tests on the instrument they employed.

\section{General characteristics of the studies}

Only four studies were randomized trials. ${ }^{6-9}$ The others used convenience or consecutive samples. With regards to methods of data collection, three studies used interviews only, ${ }^{10-12}$ six either mailed or handed questionnaires to patients, ${ }^{6,7,9,13-15}$ and five used a combination of interviews and a paper-and-pencil questionnaire. ${ }^{8,16-19} \mathrm{Almost}$ all the authors developed their own questionnaire (or questions) for measuring patient satisfaction with anesthesia services. O ne author ${ }^{11}$ selected a questionnaire previously developed and tested..$^{20} \mathrm{O}$ nly the studies in Group B presented the results of psychometric tests conducted on the scale employed to gather data. ${ }^{9,11,13,15,16,19}$

Main results on patient sati faction and psychometrics The majority of studies, whether from group A or B, reported high levels of patient satisfaction with anesthesia. H owever, when patients were given an opportunity to express themselves freely, they noted certain unsatisfactory elements in the care received from anesthesiologists.

The Group B studies, although using more rigorous methods than those in Group A, still obtained very high levels of satisfaction. O nly one study ${ }^{11}$ (in Group B) defined patient satisfaction, and none of the 
TABLE Characteristics of the studies

Group A: Studies with no psychomeric evaluation of instrument

\begin{tabular}{|c|c|c|}
\hline $\begin{array}{l}\text { Journal \& year (periodic } \\
\text { or manuscript) } \\
\text { Keep et al. (1978)1 } 0 \\
\text { (Anaesthesia) }\end{array}$ & $\begin{array}{l}\text { Population (sample) } \\
\text { (N = targeted sample) } \\
\text { Convenience sample } \\
\mathrm{N}=\mathrm{N} \text { ot mentioned } \\
\text { Types of surgery: general, thoracic, } \\
\text { ENT, dental, orthopedic, gynecology }\end{array}$ & $\begin{array}{l}\text { M ain general results on patient satisfaction and instrument } \\
\text { ( } n=\text { number of respondents) } \\
\text { - } n=100 \text { respondents } \\
\text { - All } 100 \text { patients said that they were either satisfied or very } \\
\text { satisfied with their anesthetic } \\
\text { - D evelopment of the instrument not specified }\end{array}$ \\
\hline $\begin{array}{l}\text { Burrow }(1982)^{17} \\
\text { (Anaesthesia \& Intensive } \\
\text { Care) }\end{array}$ & $\mathrm{N}=175$ patients for general surgery & $\begin{array}{l}\text { - } n=139 \text { respondents } \\
\text { - } 72 \% \text { of patients were satisfied with the time spent by the } \\
\text { anesthesiologist for the preoperative evaluation } \\
\text { - } 64 \% \text { lacked preoperative information } \\
\text { - O nly } 7.9 \% \text { answered affirmatively to a general question } \\
\text { regarding complaints, but on specific questioning } 80 \% \text { said } \\
\text { they had experienced discomfort or worse } \\
\text { - D evelopment of the instrument not specified }\end{array}$ \\
\hline
\end{tabular}

Dodds et al. $(1985)^{18}$

(Anaesthesia \& Intensive Care)
$\mathrm{N}=124$, convenience sample

Types of surgery not mentioned

- $n=121$ respondents

- Patients had a very high expectation of uneventful anesthesia ( $85 \%)$ but a significant number of patients (21\%) expressed specific fears of anesthesia ( e.g. not waking up)

- The preoperative visit was considered to be of adequate duration by 110 patients (91\%)

- Women reported a significantly higher incidence of postoperative shivering, headaches and a feeling of being cold $(P<0.05)$

- D evelopment of the instrument not specified

Preble et al. (1993) ${ }^{7}$

(Connecticut M edicine)
Randomized sample of $\mathrm{N}=2374$ patients (ambulatory $\&$ hospitalized)

Longitudinal study

(Oct. '86 - Oct. '91)

- $\mathrm{n}=1291$ respondents

- $\mathrm{H}$ igh degree of patient satisfaction for all categories: the preoperative visit ( $X=9.17 \pm 1.6)$, the postoperative visit $(X=8.33 \pm 2.7)$ and overall satisfaction $(X=9.15 \pm 1,7)$

- Postoperative visit lowest score; identified as an area of patient concern

- Although results on satisfaction levels were high, specific comments from patients revealed areas of dissatisfaction with anesthetic care

- $0.9 \%$ of the patients surveyed rated their interaction with the department as unsatisfactory in all three areas; $2.6 \%$ in two areas, $10.8 \%$ in at least one area

- D evelopment of the Patient Satisfaction Survey not specified

Penon \& Ecoffey $(1995)^{14} \quad \mathrm{~N}=\mathrm{N}$ ot mentioned

(Annales Françaises

d'Anesthésie et de

Réanimation)
Patients for ENT \& gastric surgeries
- $\mathrm{n}=90$ respondents

- $96 \%$ of patients were satisfied with the care received from anesthetists

- Personalized evaluation by the anesthetists decreased anxiety for 21 patients ( $73 \%$ of 29 patients)

- Anesthesia was perceived as the main cause of anxiety for 40 patients ( $65 \%$ of 62 patients)

- Preoperative visit by anesthetist produced a minor decrease of anxiety for 46 patients ( $59 \%$ of 78 patients) and a major decrease for 21 patients ( $27 \%$ of 78 patients)

- Development and content of the instrument not specified

- Group A ( $n=48)$, Group B ( $n=48)$, Group C $(n=48)$

- Patient evaluation of hospital, surgical, and anesthesia care was high for all groups and did not vary by group

- Increasing the number of postoperative visits does not improve physician recognition nor patient satisfaction with anesthesia services $(P<0.05)$

- Instrument: Patient Perception and satisfaction with $\mathrm{H}$ ospital and Anesthesia Care (10 questions 2 general questions and 8 more specific (grade: [1 poor] to 5 [outstanding])

- D evelopment of the instrument not specified 
TABLE Characteristics of the studies - continued

\begin{tabular}{|c|c|c|}
\hline $\begin{array}{l}\text { Brown \& al. (1997)6 } \\
\text { (M ayo Clinic Proceedings) }\end{array}$ & $\begin{array}{l}\mathrm{N}=315 \text { patients, divided into } 3 \\
\text { groups ( } \mathrm{N}=105 / \text { group): } \mathrm{A} \text { (no } \\
\text { problems), B(airway problems), } \\
\mathrm{C} \text { (cardiovascular problems) } \\
\text { Randomized (groups A and C) } \\
\text { Convenience (group B) }\end{array}$ & $\begin{array}{l}\text { - Group A ( } n=76 \text { ), Group B ( } n=83 \text { ), Group C ( } n=80 \text { ) } \\
\text { - N o significant difference between the groups regarding sat- } \\
\text { isfaction with anesthesia care ( } 98 \% \text { were very } \\
\text { satisfied or satisfied in each group ). According to these } \\
\text { results, overall patient satisfaction postoperatively is } \\
\text { unaffected by intraoperative anesthetic events }(P<0.05 \text { ) } \\
\text { - Comments of patients specified that increased collaboration } \\
\text { between doctors and nurses as well as decreased } \\
\text { waiting time before surgery augments patient satisfaction } \\
\text { - D evelopment of the instrument not specified }\end{array}$ \\
\hline $\begin{array}{l}\text { M yles \& al. }(2000)^{12} \\
\text { (British Journal of } \\
\text { Anaesthesia) }\end{array}$ & $\begin{array}{l}\mathrm{N}=17106 \text { patients for general and } \\
\text { specialty surgery }\end{array}$ & $\begin{array}{l}\text { - } \mathrm{n}=10811 \text { patients } \\
\text { - N o mention of instrument used to collect data } \\
\text { - O verall level of satisfaction with anesthesia care was } 96,8 \% \\
\text { Factors strongly associated with satisfaction: older age } \\
\text { patient, male sex and measures of increased perioperative } \\
\text { risk (co-morbidity + ASA status }>\text { III). Strong relation } \\
\text { between patient dissatisfaction and postoperative pain, nau- } \\
\text { sea, vomiting and other complications }(P<0.0005)\end{array}$ \\
\hline
\end{tabular}

Group B: Studies that included some psychometric evaluation of instrument

\begin{tabular}{|c|c|c|}
\hline $\begin{array}{l}\text { Source } \& \text { year (periodic } \\
\text { or manuscript) }\end{array}$ & $\begin{array}{l}\text { Population (sample) } \\
\text { (N = Targeted sample) }\end{array}$ & $\begin{array}{l}M \text { ain general results on patient satisfaction } \\
\text { and instrument } \\
\text { ( } n=\text { number of respondents) }\end{array}$ \\
\hline $\begin{array}{l}\text { Shevde \& Panagopoulos } \\
(1991)^{19}\end{array}$ & $\begin{array}{l}\mathrm{N}=\mathrm{N} \text { ot mentioned } \\
\text { Consecutive sample } \\
\text { M inor + major surgeries } \\
30 \% \text { ambulatory }\end{array}$ & 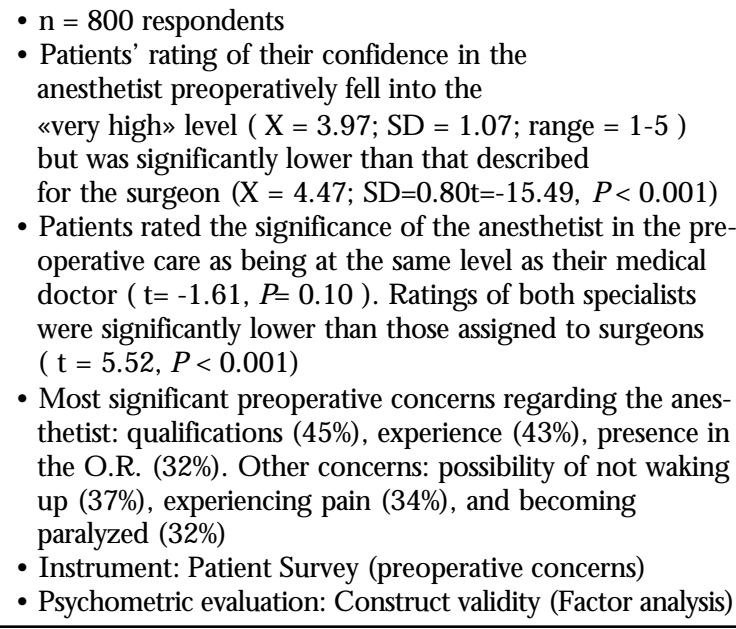 \\
\hline 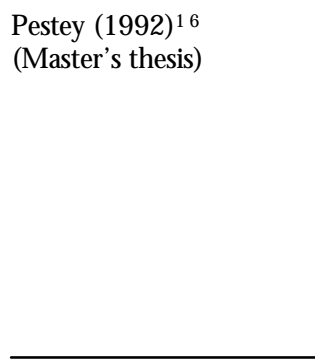 & $\begin{array}{l}\text { Stratified sample of patients for } \\
\text { elective surgery. Stratification by } \\
\text { types of anesthesia and types of } \\
\text { admission (Short-term surgery, } \\
\text { Same-day admission, Previous day } \\
\text { admission) } \\
\mathrm{N}=50 \text { patients in each group } \\
\text { All surgeries except: emergency, } \\
\text { obstetrics, transfers to ICU, pediatrics }\end{array}$ & $\begin{array}{l}\text { - } n=150 \text { respondents } \\
\text { - Satisfaction levels with the service: anesthesia staff ( } 92 \%) \text {, } \\
\text { time spent }(87 \%) \text {, fears relieved }(86 \%), \text { knowledge } \\
\text { gained ( } 82 \%) \text {, and effects explained }(74 \%) \\
\text { - No significant differences in satisfaction between same-day } \\
\text { admission, previous day admission, and short-term } \\
\text { surgery (P <0.05) } \\
\text { - Instrument: Q uestionnaire Tool } \\
\text { - D evelopment of the instrument not specified } \\
\text { - Psychometric evaluation: Reliability }\end{array}$ \\
\hline $\begin{array}{l}\text { Whitty \& al. (1996)1 } \\
\text { (Anaesthesia) }\end{array}$ & $\begin{array}{l}\text { Consecutive sample of } \mathrm{N}=172 \\
\text { patients for ophthalmic, general, and } \\
\text { maxillofacial surgeries (pilot study) }\end{array}$ & $\begin{array}{l}\text { - } n=126 \text { respondents } \\
\text { - } 67 \% \text { of patients reported that they were very satisfied with } \\
\text { their anesthetic care } \\
\text { - } 65 \% \text { of patients mentioned that they would be very happy } \\
\text { to have the same anethetis for a future operation } \\
\text { - } 55 \% \text { of patients mentioned that they would be very happy } \\
\text { to have the same anethetic for a future operation }\end{array}$ \\
\hline
\end{tabular}


TABLE Characteristics of the studies - continued

Whitty et al. (1996) 15 - continued

- Patients' perceptions of having had adequate information about the anesthetic preoperatively, $\dagger$ having had postanesthetic sequelae explained,* and having undergoing a reasonable length of time without a drink preoperatively, $\dagger$ all seemed to affect a patient's willingness to have the same anesthetic again (statistically significant results, $* P<.01$ and $+P<.05)$

- Perception of reassurance after the preoperative visit seemed to affect patients' overall satisfaction with anesthetic care $(P<0.01)$

- Focus groups used to generate patients' concerns and pool of questions

- Psychometric evaluation: Content validity

\begin{tabular}{ll}
\hline Tong et al. (1997) $)^{11}$ & Consecutive sample of $\mathrm{N}=6285$ \\
(Anesthesiology) & patients after ambulatory surgery \\
& (O phthalmology, C\&C, arthroscopy, \\
laparoscopy and 20 other types of \\
surgery)
\end{tabular}

Prospective study

Patients for ambulatory surgery (ophthalmology $60 \%$, gynecology $14 \%$ knee $14 \%$, others $12 \%$ )
- $n=2730$ respondents.

- Dissatisfaction with anesthesia was associated with a 12-fold increase in global dissatisfaction ( $P=0.0001)$

- The number of symptoms occuring $24 \mathrm{hr}$ after operation was associated with an exponential $(0.28 \times \mathrm{N})$-fold increase in dissatisfaction with anesthesia for $\mathrm{N}$ number of symptoms ( $P=0.0001)$

- Intraoperative and postoperative adverse outcomes were the major causes of dissatisfaction with anesthesia (88\%)

- Instrument: Patient Q uestionnaire (Abramovitz \& al., 1987)

- Psychometric evaluation: Reliability

\begin{tabular}{ll}
\hline Dexter et al. (1997) 13 & Patients for ambulatory surgery \\
(Anesthesiology) & (ophthalmology $60 \%$ gynecology \\
& $14 \%$ knee $14 \%$ others $12 \%)$
\end{tabular}

- $\mathrm{n}=80$ respondents

- Patients overall score on ISAS (mean \pm SD): $2.1 \pm 0.87$ (max: 3.0)

- Instrument: I owa Satisfaction with Anesthesia Scale (ISAS)

- Psychometric evaluation: Reliability, content validity, convergent validity

\begin{tabular}{ll}
\hline Fleisher et al. (1999) & Randomized sample of $N=371$ \\
(J Clin Anesth) & $\begin{array}{l}\text { outpatients without adverse } \\
\text { anesthetic events }\end{array}$
\end{tabular}

- $n=229$ respondents

- Patients in the group that received an Anesthesiology Consultant Report (ACR) were more satisfied with the management of their pain and other symptoms $(P<0.05$, by Wilcoxon rank sums) and were more satisfied overall with the quality of the anesthesia care $(P<0.01$, by Wilcoxon rank sums). Patients deemed the quality of their anesthetic care as excellent in the ACR group compared to control $(83 \%$ vs $67 \%$, $P<0.01)$

- Instrument: Postoperative Questionnaire

- Development of the instrument not specified

- Psychometric evaluation: Reliability six studies included a conceptual framework of their constructs. Furthermore, no study included other questionnaires to control for confounding variables, such as level of psychological distress or social desirability, even though these variables may affect a patient's ability to properly complete a questionnaire on satisfaction and to answer rationally.

The psychometric testing of the scales was performed in a variety of ways. Shevde \& Panagopoulos, ${ }^{19}$ presented a factor analysis of the data to reveal the presence of four distinct factors (specific complications of anesthesia, characteristics of the anesthesiologist, anxiety about being hospitalized and pain). No other testing was performed on their scale. Pestey ${ }^{16}$ evaluated the reliability of her scale using a test-retest with short term surgery patients only $(n=38)$. Pearson correlation coefficients were calculated for each individualized questions ( $Q 2=0.76, Q 3=0.88, Q 4=0.76, Q 5=0.79, Q 7=0.66$ ). Whitty et al., ${ }^{15}$ developed a scale using patient focus groups, comments from anesthesiologists and a theory of patient satisfaction. Content validity was verified with patients, anesthesiologists, experts on questionnaire design, and a "fog index" (M icrosoft Word software that screens a text and identifies words exceeding the level of 
grade 6). No other testing was performed on their scale. Tong et al. ${ }^{11}$ used a Kappa (interrater agreement) between nurses and anesthesiologists to assess the relia bility of their two scales (a standardized check-off form for adverse events, a 24-hr postoperative telephone questionnaire). Values of $k>0.9$ were obtained for both scales. As to the reliability of the questions on satisfaction, these authors relied on the psychometric informa tions obtained in a previous study ${ }^{20}$ and did no testing of the data (data obtained using the questionnaire of Abramovitz and colleagues). Dexter and colleagues ${ }^{3}$ performed various tests on their new scale (I owa Satisfaction with Anesthesia Scale [ISAS]) and obtained a value of 0.80 for internal consistency (Cronbach's Alpha), and correlations of $R^{2}=0.74$ (after one hour) and $R^{2}=0.76$ (after four days) for stability (test-retest). Content validity (evaluation of the extent to which the method of measurement includes all the major elements relevant to the construct being measured) of the ISAS was verified once, before the study began; the verifica tion was performed by professionals. To establish convergent validity, the authors compared patients' overall scores to those predicted by their anesthesia provider $\left(R^{2}=0.23, P>0.01\right)$. Fleisher et al. ${ }^{9}$ relied on the correlation between the question regarding quality of care and the one regarding satisfaction with pain management to verify the internal consistency of their instrument. A Cronbach's Alpha of 0.62 was obtained. No other testing was performed on the scale.

\section{Discussion}

O verall, surveys of patient satisfaction presented in this review yielded very positive results. Unfortunately, these results are often accepted at face value and considered as the sole indicator that the services offered by the department of anesthesiology, as evaluated by patients, are adequate. Since the results are so favourable, the incentive to improve further the quality of services provided is slight. ${ }^{11} \mathrm{O}$ nly one author ${ }^{1}$ questioned the high level of satisfaction suggested by their results: "This apparent satisfaction should therefore give the anaesthetist little cause for self-congratulation, since it implies that the patient neither expects nor demands a high standard of service or expertise from his anaesthetist...".

Another possible explanation for these positive results is that most researchers have a bias towards measuring satisfaction. In other words, they do not allow elements of dissatisfaction to emerge from their surveys. Q uestionnaires are oriented more towards the researchers' desire for positive results. They do not offer open-ended questions where patients can advance opinions or express dissatisfaction concerning elements covered or not by the survey.

O nly one study ${ }^{1}$ presented a clear definition of the concept of patient satisfaction. As for the remainder, since no definition was provided, it is not clear what these studies truly measured. For example, the ISAS scal $e^{13}$ appears to measure more patients' physical condition at a precise moment in time than the patients'satisfaction regarding anesthesia services. Further, none of the 14 studies presented a conceptual framework relative to patients' satisfaction with anesthesia services, thus leaving the reader in the dark as to what variables might explain the underlying concept.

Another important cause for concern is that no study attempted to control for any confounding variables. Respondents might not be answering the items of primary interest for the reasons we assume. There may be other motivations influencing their responses. O ne type of motivation that can be assessed fairly easily is social desirability. Social desirability is defined as the motivation of a person to present herself or himself in a way that society regards as positive. ${ }^{21}$ If respondents are influenced by social desirability, they may distort their answers and thus invalidate their evaluation of satisfaction. For instance, in the Dexter et al. study, ${ }^{13} 90 \%$ of the respondents, in the first version of their instrument, answered that they totally agreed with the statement "I like my anesthetist". Also, in the study by Keep et al. ${ }^{10}$ one patient who had been awake during her esophagoscopy mentioned that she was satisfied with the anesthetic but would prefer to be asleep the next time! D id social desirability influence or help to explain the high levels of satisfaction obtained? Since none of the 14 studies reviewed controlled for social desirability, the validity of the results remains open to question. Perhaps the use of $M$ arlow $\&$ Crowne's abridged social desirability scale, ${ }^{22}$ along with a patient satisfaction scale, would help to increase the validity of the results obtained by excluding respondents vulnerable to social desirability.

In at least four of the studies reviewed, $, 7,8,13,17$ patients may have been influenced by either the presence of the anesthesiologist or the suspicion that the anesthesiologist could identify them. For instance, if the anesthesiologist remains nearby while the patient is completing the questionnaire, as occurred in three studies $^{10,13,17}$ the patients' right to anonymity and confidentiality is not protected. Patients cannot be expected to express their comments, suggestions or grievances if they have even the slightest doubt that their right to confidentiality and anonymity is not being respected. ${ }^{23}$

Few clinicians are aware of the importance of psy- 
chometric evaluation in the development of a new scale. ${ }^{4}$ For example, D exter et al. ${ }^{13}$ tested for reliability after an interval of four days, mentioning that "the test-retest method of assessing reliability is sensitive to the time interval between testing. The longer the time interval, the lower is the reliability". Yet, for paperand-pencil measures, experts recommend a waiting period of two weeks to a month between tests, the goal being to keep subjects from remembering their answers to the first test, which could lead to an overestimation of the test's reliability. ${ }^{21,24}$ Further, it is considered irrelevant to perform test-retest evaluation with instruments measuring patient satisfaction since this concept may vary in time and it is also influenced by the effect of memory which is an undesirable consequence in the measurement of this concept. It is more appropriate to focus on obtaining reliable results regarding the internal consistency of the scale, thus an elevated Alpha of Cronbach. Similarly, having a small developmental sample (less than 10 subjects per items) to evaluate internal consistency (Cronbach's Alpha) can produce inappropriately favourable results. ${ }^{21,25}$ When the ratio of subjects to items is relatively low and the sample size is small, correlations between items will be influenced by chance to a substantial degree. An Alpha of Cronbach of 0.80 using only 49 subjects, on a scale of 11 items, ${ }^{13}$ should therefore be questioned. Finally, even the employment of a very large sample ${ }^{12}$ (10,811 patients) did not compensate the evidence and consequences of a lack of rigour in the methods and the development of the instrument to measure patient satisfaction. I ndeed, in the study by $M$ yles et al., ${ }^{12}$ the variable "patient satisfaction», considered as a major outcome, was measured by a question with only three choices of answer and results dichotomized between satisfied vs somewhat dissatisfied-dissatisfied. Such strategy is not very well considered, ${ }^{26}$ and it does not generate enough variance in the distribution of the data collected. In addition, services offered by anesthesiologists include many components. We doubt that such a complex issue can be properly evaluated by only one question. Thus there are serious doubts about the significance of results obtained with an unvalid and unreliable instrument. Further, even though the authors recognize the influence of social desirability on respondents, no measures were taken to evaluate the impact of this important confounding variable. ${ }^{27}$

The process that must be followed to obtain valid results is complex. It involves more than writing up a few questions and passing them along to the desired population. As well, a newly developed scale must be tested to verify what it really measures, in view of pro- ducing valid results. The initial testing of a scale is not sufficient to verify all of the attributes of both reliability and validity of the scale. Results obtained with a new scale must therefore be interpreted with caution. For the sake of psychometrics, one must "sacrifice" at least one sample; only then can one pretend to significant results on the concept measured. ${ }^{26}$

In a first trial, such psychometric measures as establishing content validity, internal consistency and construct validity (determines whether the instrument actually measures the theoretical construct it purports to measure) are considered sufficient for evaluating the properties of a scale, taking into account that a theoretical construct of the variables of the study is presented at first. ${ }^{26}$ Indeed, it is inappropriate to try to perform every psychometric test available on a new scale in a single study. Achieving the complete psychometric profile of a new scale takes time. ${ }^{26}$ Any new instrument must go through several specific phases and trim before it can be considered to be reliable and valid. Also, the control of major confounding variables is essential to reduce the "contamination" of the main variable (e.g. satisfaction) to be measured by an instrument.

The task of maintaining reliability and validity of instruments is never concluded. M easurement devices are nearly al ways subject to the effects of social context. Values and practice patterns change, individuals think differently about a number of matters, and terminologies go out of fashion. ${ }^{28}$ Scale development is a continuous and retroactive process. Finally, care should be taken when attempting to generalize results obtained with a new instrument of unestablished validity and reliability; otherwise, one risks making false assumptions concerning the population from which the sample was drawn.

\section{Conclusions}

The perceptions of patients, along with quality assurance, are an important component of the evaluation of the quality of services in anesthesiology. Even though perceptions are subjective, this information is important to anesthesiologists. Indeed, patients offer an unique perspective for evaluating the nontechnical aspects of medical care. ${ }^{29} \mathrm{H}$ owever, to be useful and valid for clinicians and researchers and to engender improvement in the practice of anesthesiology, such information must be collected using rigorous methods and a valid, reliable instrument derived from a conceptual framework. It is doubtful that the results of the studies presented in this review truly represent perceptions of patients regarding the anesthesia care received.

As with all standardized data collection, creating and performing high quality surveys of patients' perceptions can be challenging. Valid and reliable patient 
survey data can enable practitioners to identify areas for improvement, and demonstrate to external reviewt ers the quality of care they provide to their patients. ${ }^{29}$ That is why the development of valid and reliable instruments to measure patient satisfaction must adhere to specific psychometric requirements and control for major confounding variables. The procedure is complex. U se of a non-validated and/ or non-specific instrument will only produce unreliable and meaningless results. Generalization of results from a given patient population is hazardous, especially when the initial methods are questionable.

Finally, this review allowed emphasis on the absence of appropriate instruments to measure patient satisfaction with anesthesia services, the many biases present in the methodology employed, the lack of rigour regarding the psychometric testing of the instrument used and also the very high levels of satisfaction usually obtained by surveys on patient satiffaction with anesthesia services to be demistifyed. We proposed solutions to increase the validity of the measurement of patients' satisfaction regarding the services provided by anesthesiologists.

\section{Acknowledgements}

The authors would like to acknowledge the outstanding secretarial support of M rs. Diane Charbonneau, $\mathrm{N}$ icole Charbonneau and Céline Charbonneau from Accès Secrétariat, Blainville $(\mathrm{Q} c)$. We are also grateful to $\mathrm{Mrs}$. Wendy $D$ ayton, specialist in medical redaction, for a thorough review of an earlier draft of this manuscript.

\section{References}

1 Duncan P. Q uality: a job well done! (E ditorial) Can J Anaesth 1993; 40: 813-5.

2 Bierstein K. Consumer satisfaction surveys in anesthesiology practice. American Society of Anesthesiologists N ewsletter 1996; 60: 26-9.

3 Eagle CL, D aviesJ M. Current models of "quality" - an introduction for anaesthetists. Can J Anaesth 1993; 40: 851-62.

4 Fung $D$, C ohen M M. M easuring patient satisfaction with anesthesia care: a review of current methodology. Anesth Analg 1998; 87: 1089-98.

5 C ook D. Systematic reviews: the case for rigorous methods and rigorous reporting. Can J Anaesth 1997; 44: 350-3.

6 Brown DL, Warner ME, Schroeder DR, O fford KP. Effect of intraoperative anesthetic events on postoperative patient satisfaction. M ayo Clin Proc 1997; 72: 20-5.

7 Preble LM, Perlstein L, K atsoff-Seidman, L, O'C onnor TZ, Barash PG. The patient care evaluation system: patients' perceptions of anesthetic care. Connecticut $M$ ed 1993; 57: 363-6.

8 Zvara D A, N elson J M, Brooker R F, et al. The importance of the postoperative anesthetic visit: do repeated visits improve patient satisfaction or physician recognition? Anesth Analg 1996; 83: 793-7.

9 Fle sher $L A, M$ ark $L$, Lam J, \& al. D isseminating information using an anesthesiology consultant report: impact on patient perceptions of quality of care. J Clin Anesth 1999; 11: 380-5.

$10 \mathrm{~K}$ eep PJ, Jenkins JR. From the other end of the needle. The patient's experience of routine anaesthesia. Anaesthesia 1978; 33: 830-2.

11 Tong $D, C$ hung $F$, W ong D. Predictive factors in global and anesthesia satisfaction in ambulatory surgery patients. Anesthesiology 1997; 87: 856-64.

12 M yles PS, Williams D L, $H$ endrata $M, A$ nderson $H$, Weeks A M . Patient satisfaction after anaesthesia and surgery: results of a prospective survey of 10811 patients. Br J Anaesth 2000; 84: 6-10.

13 D exter F, A ker J, Wright WA. D evelopment of a mea sure of patient satisfaction with monitored anesthesia care. The l owa satisfaction with anesthesia scale. Anesthesiology 1997; 87: 865-73.

14 Pen on C, Ecoffey C. Patients opinion on the quality of anaesthetic management. (French) An Fr Anesth Réanim 1995; 14: 374-5.

15 Whitty PM, Shaw IH, Goodwin DR. Patient satisfaction with general anaesthesia. Too difficult to measure? Anaesthesia 1996; 51: 327-32.

16 Pestey ME. Patient satisfaction with anesthesia services delivered in the cost containment atmosphere of healthcare today. U npublished master thesis. $\mathrm{N}$ ew $\mathrm{H}$ aven, Connecticut: Southern Connecticut State U niversity, 1992.

17 Burrow BJ. The patient's view of anaesthesia in an Australian teaching hospital. Anaesth Intensive $\mathrm{C}$ are 1982; 10: 20-4.

18 D odds C P, H arding MI, M ore D G. Anaesthesia in an Australian private hospital: the consumer's view. Anaesth Intensive Care 1985; 13: 325-9.

19 ShevdeK, Panagopoulos G. A survey of 800 patients' knowledge, attitudes, and concerns rearding anesthesia. Anesth Analg 1991; 73: 190-8.

20 A bramovitz S, CotéA A, BerryE. Analyzing patient satisfaction: a multi-analytic approach. Q uality Review Bulletin 1987; 13: 122-30.

21 D eV ellis R F. Scale development: Theory and A pplications. London: Sage Publications, 1991.

22 Strahan R, Gerbasi KC. Short homogenous versions of the $\mathrm{M}$ arlow-Crowne social desirability scale. J Clin Psychol 1972; 28: 191-3.

23 Strasser S, D avis R M. M easuring patient satisfaction for 
improved patient services. Ann Arbor, M ichigan:

$\mathrm{H}$ ealth Administration Press, 1991.

24 N unnally JC, Bernstein IH. Psychometric Theory, 3rd ed. M ontreal: M cG raw H ill Inc., 1994.

25 Streiner DL, N orman GR. H ealth M easurement Scales. A Practical Guide to their D development and U se, 2nd ed. Oxford: O xford U niversity Press, 1995.

26 Crocker L, A lgina J. Introduction to Classical and Modern Test Theory. Fort Worth: H arcourt Brace Jovanovich C ollege Publishers, 1986.

27 Le M ay S, H ardy J-F, T aillefer M-C, D upuis G. I nappropriate methods for patient satisfaction (L etter). Br J Anaesth 2000; 84: 821.

28 WilliamsMA. Instrument development: always unfinished (E ditorial). Res $\mathrm{N}$ urs $\mathrm{H}$ ealth 1989; 12: iii-iv.

29 Epstein KR, Laine C, Farber N J, N elson EC, Davidoff F. Patients' perceptions of office medical practice: judging quality through the patients' eyes. Am J M ed Qual 1996; 11: 73-80. 